\title{
Factors Influencing Compliance with Immunization Regimen among Mothers in Ibadan, Nigeria
}

\author{
Fatima. R .Rahji ${ }^{1}$ and Chizoma .M. Ndikom ${ }^{2}$, \\ RN, RM, BNSc ${ }^{1}, \quad$ RN, M.Sc. FWACN ${ }^{2}$ \\ Nurse Educator, School of Midwifery, Eleyele, Ibadan, Nigeria . \\ Lecturer, Department of Nursing, College of Medicine, University of Ibadan, Ibadan, Nigeria
}

\begin{abstract}
:
Introduction: Immunization is one of the world's most cost-effective health interventions that helps prevent childhood diseases. However, many infants are not usually fully vaccinated especially in developing countries. This contributes to mortality Vaccine-Preventable Diseases (VPD) in children. This study examines factors influencing compliance with immunization regimen among nursing mothers in Moniya Community Ibadan, Nigeria.

Design and methods: The study used a cross-sectional survey to collect data among nursing mothers. Systematic sampling method was used to select the households while the women were purposively selected. Interviewer administered questionnaires were used to collect data from the 153 respondents.

Results: The study showed that $62.8 \%$ complied fully while $37.2 \%$ did not. Some of the respondents $(19.6 \%)$ did not take any vaccines for their children. Out of this, $65.4 \%$ cited child sickness as the reason for their failure to immunize their children. Side effects, waiting time, number of visits, and attitude of health care workers were other reasons for not immunizing their children.

Conclusions: There should be an improvement in availability and accessibility of vaccines, immunization time should be more flexible, prompt attention and service to mothers and that health workers should be patientfriendly.
\end{abstract}

Keywords: Compliance, Immunization Regimen, Vaccine-Preventable Diseases.

\section{Introduction}

Child mortality is a challenge in many developing nations. The six child killer diseases identified by the World Health Organization (WHO) are tuberculosis, whooping cough, diphtheria, tetanus, poliomyelitis and measles. Yellow fever outbreak in Nigeria led to its inclusion in the latest immunization regimen ${ }^{1}$. Immunization coverage against hepatitis B has been increasing since 1990s. More than 160 countries now include hepatitis B in their immunization schedules. These diseases combined with malnutrition, kill an estimated 400-450 Nigerian children per day ${ }^{1}$. As many as four to five times this number of children is handicapped for life by blindness, deafness, lameness and mental retardation ${ }^{2}$

Immunization is an inexpensive and increasingly easy to administer strategy which when combined with improved nutrition and sanitation saves children ${ }^{3 .}$ In most developed nations, immunization programmes have had dramatic success in reducing morbidity and mortality rate significantly. Such programmes have helped in the eradication of diphtheria, measles, neonatal tetanus, pertusis and poliomyelitis since $1993^{4}$. Immunization has saved over 20 million lives in the last two decades. More than 100 million infants are immunized each year. This saves more than 3 million lives annually. Global mortality attributed to measles decline by $78 \%$ from an estimated 733,000 deaths in 2000 to 161,260 deaths in 2008. The prevalence of polio had decline dramatically since 1990. The number of polio cases world wide as of 2009 was 1606 and as of May 2010 it was $115^{5}$.

Immunization is defined as the creation of immunity against a particular disease. It could be the treatment of an organ and/ or making a body immune to subsequent attack by particular pathogens through giving of vaccine ${ }^{6.7}$. These vaccines protect individuals at risks of acquiring infection by inducing a variety of immune mechanisms. Immunity so acquired can be active or passive.

\section{National Programme On Immunization}

The National Programme on Immunization (NPI) is one of the components of Child Survival Programmes. NPI was designed to ensure that vaccination facilities are distributed to wider community coverage, using various means such as health education, provision of vehicles, the cold chain technique etc ${ }^{8}$. Since immunization programs were launched in low- and middle-income countries worldwide in the mid-1970s, most countries have been using the same standard package of six vaccines. Later, hepatitis B vaccine was added to the list ${ }^{8}$. With a view to improving child health, the Nigerian government has introduced pentavalent vaccine into her routine immunization schedule. Pentavalent vaccine is a combination of five vaccines-in-one that 
prevents diphtheria, tetanus, whooping cough, hepatitis $b$ and haemophilus influenza type $b$, all through a single dose

The Pentavalent vaccine will replace the DPT vaccine in Nigeria's routine immunization schedule. Pentavenlent vaccines come in two separate formulations that is Liquid based and Liquid +lyopylized.

The new routine immunization schedule is:

$\begin{array}{lc}\text { AGE } & \text { ANTIGENS (VACCINES) GIVEN } \\ \text { Birth } & \text { BCG, OPV0, HepB0 } \\ 6 \text { weeks } & \text { OPV1, Pentavalent 1, OPV 1 } \\ 10 \text { weeks } & \text { OPV2, Pentavalent 2, OPV 2 } \\ 14 \text { weeks } & \text { OPV3, Pentavalent 3, OPV 3 } \\ 9 \text { months } & \text { Measles, Yellow Fever } \\ 9 \text { months } & \text { Vitamin A (First Dose) } \\ \text { 15 months } & \text { Vitamin A (Second Dose) } \\ \text { Immunization and Disease Prevention in Nigeria }\end{array}$

Today immunization has reduced the incidence, reoccurrence and regeneration of childhood diseases in Nigeria. Data from the 2008 Nigeria Demographic Health Survey indicate that infant mortality rate was 75 deaths per 1,000 live births. The under-five mortality rate was 157 per 1,000 live births. However, child mortality rate is low in urban areas than in rural areas. There is also variation in the mortality rate across the geopolitical zones of the country. The infant mortality and under-five mortality rates are highest in the North East and lowest in the South West ${ }^{7}$. This translates to one in every six children born in Nigeria dies before their fifth birthday. The mortality rate is 88 deaths per 1,000 children surviving to 12 months of age ${ }^{9}$

In Oyo State, routine immunization coverage in 2009 was above $70 \%$ for most antigens ${ }^{10}$. Also the state has been polio free in the last 14 months. Oyo State's population of under one year old was 247,287, and under 5 years 1,236,434. Infant mortality rate in 2007 was 60/1000 live births while under five mortality rate in 2007 was $64 / 1000$ live birth. Infant mortality rate in 2009 was $21 / 1000$ live birth. Under-five mortality rate in 2009 was 42/1000 live births. The number of children under 1 year that were fully immunized in 2007 were 90,906 while the number of children under 1 year that were fully immunized in 2009 were $255,199^{10}$. These results were attributed to the supplemental immunization activities embarked on in the state.

In Nigeria, the percentage of children aged 12-23 months who received at least one dose of the traditional vaccines by their fifth birthday rose from $60.9 \%$ to $69.4 \%$ indicating that access and uptake had improved ${ }^{9}$. Yet the percentage of fully immunized with all doses before 12 months of age fell from $14.3 \%$ in 1999 to $13 \%$ in 2003 and drop-out between first and third dose of DPT increased from $45.7 \%$ to $48.1 \%$, indicating growing problems with continuity of routine immunization services.

A comparison of the 2008 NDHS results with those of the earlier surveys shows there has been an increase in the overall vaccination coverage in Nigeria from $13 \%$ in 2003 to current rate of $23 \%$. However, the percentage of children with no immunization has not improved for the same period as this stood at $27 \%$ in 2003 and $29 \%$ in $2008^{9}$. Despite the slight improvement, it is still low.

\section{Concept of Compliance}

Compliance is cooperative performance and adherence to prescribed therapy as recorded in the clinic record at a given period ${ }^{11}$ and that compliance criteria included among other things frequency of keeping clinic appointments. According to ${ }^{12}$, compliance is the client's physical presence at the health unit or hospital on the appointment day to receive the prescribed care. In the context of this study, the term compliance is defined or conceptualized as receiving the required number of doses of vaccines at the appropriate age as shown on the immunization schedule table and recorded in the child's record card.

\section{Barriers to Childhood Immunization Compliance in Nigeria}

Nigeria is making efforts to strengthen its routine immunization so as to reduce the burden of vaccine preventable diseases, especially in Northern Nigeria. ${ }^{13}$ stated that one of the barriers to immunization in Nigeria is the frequent undersupply of vaccines and the need for repeated visits often led to incomplete immunization of children in those that have no easy access to a Primary Health Care

According to ${ }^{13}$ myths, rumors, ignorance and suspicion are major factors found to hinder immunization. In the sample, $16 \%$ believe that the diseases are caused by evil spirit, witchcraft and heat. Some $25 \%$ have never heard of measles immunization. Another $27 \%$ did not believe immunization was effective while $4 \%$ were not allowed to go for immunization by their husbands. Some women believed their children had received some vaccine; Many women felt that immunization was not necessary because the child was not sick. In the same veil,

In another study $b^{2}$ which she conducted a study in Northern Nigeria to compare mother's reasons for nonimmunization and partial immunization of children under five years in Northern Nigeria, to determined the 
association between specific reasons and future intention to immunize children. Most common reasons for nonimmunization were lack of knowledge about childhood immunization schedule and where to sources for it. Other reasons include lack of awareness about health benefits of immunization

The most common reasons for incomplete immunization were inadequate vaccine supply in health facilities ${ }^{2}$. About one- fifth of the women gave reasons that revealed their lack of knowledge about immunization benefits, routine immunization schedule and the required number of doses. Some women believed that their children were too young to receive specific vaccines, particularly those involving the use of needles and syringes. More over few women believed that their child had received some vaccines and were apparently well and thriving there was no need for additional vaccines. Some women also believed that too many vaccines could be harmful to the child. Large percentage of women gave reasons that showed total reliance on immunization campaigns for child immunization. Excuses tendered such as waiting for immunization Officers to come back and lack of availability of other vaccines during the exercise revealed lack of understanding of the routine immunization as a source of child immunization.

Some women gave reasons related to mother's unavailability, including sickness, travel time and time constraints. A few mentioned purdah.

Provider's attitudes and long waiting period were cited by few mothers as their reason for not taking additional immunization for their children. Indeed a few women were frustrated because they had visited the facility more than one time with no vaccines on ground, absence of service providers or disrespectful providers. A study by ${ }^{14}$ compared the immunization cards of all the children aged five years and below admitted into the peadiatric wards of the University of Calabar Teaching Hospital, Calabar, Nigeria with the mothers 'history of their children immunization status. The results of the study showed that only $560(60.9 \%)$ were fully immunized for age. $244(26.6 \%)$ partially immunized and $115(12.5 \%)$ had no form of immunization. The prevalence rate of missed opportunity was $39.1 \%$. Most of these patients were in the in the low lower socio-economic groups. The commonest reason for missing immunization was illness of the child at the time of immunization.

This is an indication that health workers should intensify their efforts in educating mothers on contraindications for immunization. In a study by ${ }^{15}$, which evaluated for timeliness in receiving vaccines and the completion rates of the schedule, about $30 \%$ of the children presented after four weeks of age for their first immunization; $18.9-65 \%$ of the children were delayed in receiving various vaccines compared to the recommended ages for receiving the vaccines. Only $44.3 \%$ children were fully immunized. This is an indication that health workers should intensify their efforts in educating mothers on benefits of immunization. Study on compliance rates in Kern country, California and found that parents sited non-compliance as being due mainly to child's illness, procrastination and lack of knowledge about immunization and where to obtain services ${ }^{16}$. This study is in support of findings by ${ }^{2}$

Also, ${ }^{17}$ found that non-minority children with parents of higher socio-economical background were far more likely to have complete immunization. Another study to identify vaccination barriers in children 12-24 months and found that of the parents who were surveyed, only $20 \%$ reported that their children were currently up-to-date with their immunizations ${ }^{18}$.

\section{Theoretical Consideration: The Health Belief Model.}

The health belief model is used in this study. The model explains reasons for compliance behavior. The model is known to be most successful when applied to preventive health services such as immunization. It has been used extensively to organize theoretical predictors of preventive health actions including individual perceptions of diseases, individual perception of preventive actions and modifying factors such as social and demographic and structural characteristics

The model states that individuals engage in preventive health behaviour based on three main factors. These factors are perceived vulnerability, perceived severity and perceived benefits. This means that a person would have to believe that he or she is susceptible or vulnerable to a disease in order to take any action. The value of compliance is therefore based on the probability that in the client's view, compliance will reduce the perceived threat and not be too costly in money, time and emotional energy ${ }^{19}$. Hence, the preventive action taken by an individual depends on the individual's perception that he or she is personally susceptible and that occurrence of the disease would have at least some severe implication of a personal nature. The assumption here is that taking action reduces susceptibility. The perception of threat is also affected by modifying factors. These include demographic, social, psychological and structural variables. These can influence both perception and corresponding cue necessary to instigate action.

The health belief model is selected for this study because it can help to explain some factors responsible for compliance with immunization. The elements of the model can assist the researcher in designing the health education interventions that could influence mother's readiness to take their children to immunization 
centers. This is by emphasizing the benefits of compliance and by removing obstacles that might prevent compliance.

In the context of this study, perceived susceptibility means a high probability of susceptibility to the child killer diseases. The threat posed by these diseases plus the emphasis on the value of prevention by various information sources are assumed to stimulate individuals to take preventive action provided the modifying factors are favourable. That is, there is the availability of resources to aid the action at affordable cost, accessibility to the resources and even distribution of the resources.

\section{The Framework On Health Belief Model}

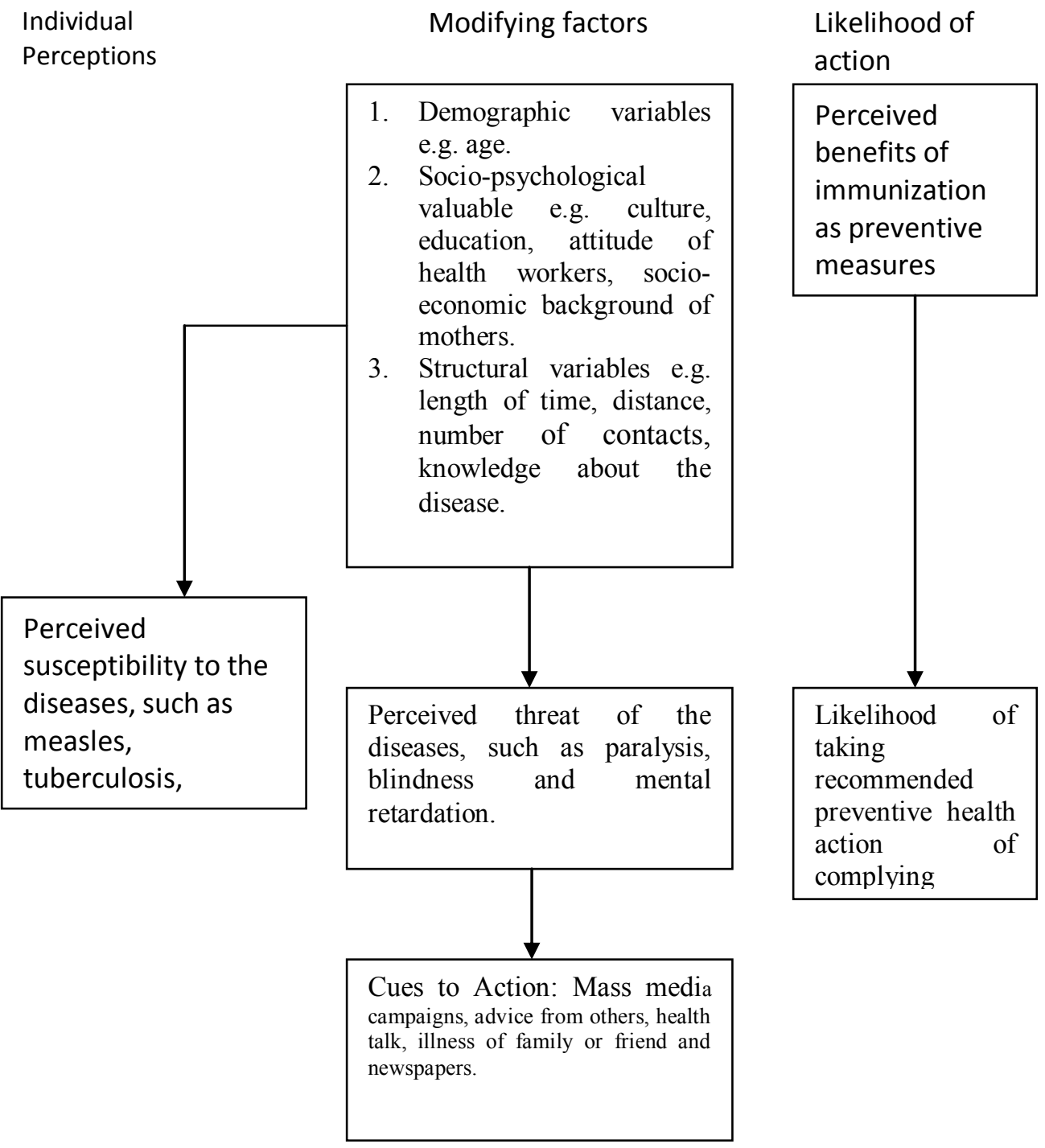

Figure 1: Schematic flow of the Theoretical Framework Adopted for the study

\section{Design and methods}

A cross sectional survey was carried out among nursing mothers with children of 0-12 months in Moniya Area, Ibadan, Oyo State, Nigeria. This study area was purposively selected as a first stage in the sampling process. Systematic sampling method was used to select the households while the women were purposively selected. 123 houses were counted to be in the area. 40 houses selected at an interval of five houses for a total of 160. In all, 160 houses were sampled. This constitutes the second stage of sampling. In the third stage of sampling a nursing mother was purposively selected in each house. However, where there was only one nursing mother she was automatically interviewed. A Post data collection analysis indicated that seven of the questionnaires contained mismatched information and so were discarded. A sample size of 153 respondents was finally used for the subsequent analysis. 


\section{Method of Data Analysis}

Descriptive statistical technique was used to analyze the data. Initial analysis involved the generation of frequency tables, while further analysis involved cross tabulation to explore statistical relationships between variables. The data were also subjected to chi-square analysis. The statistical significance was set at $\mathrm{P}<0.05$. The respondents were grouped into two: compliers and non-compliers. This was done to make comparison and to find out if the identified factors actually affected compliance with immunization regimen. The SPSS software was used in the analysis of the data.

\section{Results and Discussion}

Table 1: Socio-demographic characteristics of the respondents

\begin{tabular}{|c|c|c|}
\hline Variables & $\begin{array}{l}\text { Frequency } \\
N=153\end{array}$ & Percentage \\
\hline $\begin{array}{l}\text { Age (years) } \\
15-25 \\
26-35 \\
36-45 \\
\end{array}$ & $\begin{array}{l}69 \\
78 \\
6 \\
\end{array}$ & $\begin{array}{l}45.1 \\
50.9 \\
4.0 \\
\end{array}$ \\
\hline $\begin{array}{l}\text { Marital Status } \\
\text { Married } \\
\text { Single } \\
\text { Divorced/Separated } \\
\end{array}$ & $\begin{array}{l}141 \\
6 \\
6 \\
\end{array}$ & $\begin{array}{l}92.2 \\
3.9 \\
4.0 \\
\end{array}$ \\
\hline $\begin{array}{l}\text { Educational qualification } \\
\text { Primary } \\
\text { Secondary } \\
\text { Polytechnic } \\
\text { University } \\
\end{array}$ & $\begin{array}{l}33 \\
93 \\
18 \\
9\end{array}$ & $\begin{array}{l}21.6 \\
60.8 \\
11.8 \\
5.8 \\
\end{array}$ \\
\hline $\begin{array}{l}\text { Religion Affiliation } \\
\text { Islam } \\
\text { Christianity } \\
\text { Traditional }\end{array}$ & $\begin{array}{l}87 \\
63 \\
3 \\
\end{array}$ & $\begin{array}{l}56.9 \\
41.2 \\
2.0 \\
\end{array}$ \\
\hline $\begin{array}{l}\text { Occupation } \\
\text { Farming } \\
\text { Housewife } \\
\text { Civil servant } \\
\text { Trading } \\
\text { Students } \\
\text { Combined (trading and civil service) }\end{array}$ & $\begin{array}{l}3 \\
30 \\
15 \\
78 \\
3 \\
24\end{array}$ & $\begin{array}{l}2.0 \\
19.6 \\
9.8 \\
51.0 \\
2.0 \\
15.6\end{array}$ \\
\hline
\end{tabular}

Table 1 shows that $69(45.1 \%)$ respondents were within the age range of 15-25 years. In addition to this, $(50.9 \%)$ of the respondents were within the age range of 26-35 years. Only (4.0\%) were aged 36-45 years. This implies that about $96 \%$ of the respondents were within their active reproductive age. Marital status shows that $(92.2 \%)$ respondents were married, While 3.9 percent of the sample were single parent while $2.0 \%$ were divorced and the remaining $2.0 \%$ were separated.

The table also shows, that $(60.8 \%)$ of the respondents were secondary school graduates. $21.6 \%$ have primary school education. It also shows that the respondents were predominantly Muslims $(56.9 \%)$ while Christians represent about (41.2\%) of respondents. African traditional believers were only $2.0 \%$ respondents. Also $(51.0 \%)$ were traders. Only $(9.8 \%)$ were civil servants while $(19.6 \%)$ of the respondents were full time housewives.

TABLE 2: Compliance Ratings of the Respondents

\begin{tabular}{|l|l|l|l|l|}
\hline Item & Yes & \%age & No & \%age \\
\hline Taken vaccines at least once & 123 & 80.4 & 30 & 19.6 \\
\hline Last child fully immunized & 96 & 62.8 & 57 & 37.2 \\
\hline Aware of information on child's card & 96 & 62.8 & 57 & 37.2 \\
\hline worry over side effect & 150 & 98.0 & 3 & 2.0 \\
\hline Work allows me & 150 & 98.0 & 3 & 2.0 \\
\hline Aware of service points & 100 & 65.4 & 53 & 34.6 \\
\hline Vaccine availability & 147 & 96.1 & 6 & 3.9 \\
\hline
\end{tabular}

Table 3 shows the compliance ratings of the respondents based on Yes or No answers. About $80.4 \%$ affirmed that they have taken at least one vaccine while $19.6 \%$ claimed they have not taken any vaccine for their children. More so, $62.8 \%$ have fully immunized their last child while the remaining $37.2 \%$ of the respondents did not immunize their children fully.. Some $98.0 \%$ of the respondents contended that they worry about the side effects of immunization. Only $2.0 \%$ did not worry over the side effects. Furthermore, $98.0 \%$ claimed that their 
occupations allow them to take their children for immunization. Only $2.0 \%$ said that their occupations did not give them much time to take their children for immunization. Also $98.0 \%$ of respondents stated that their religious beliefs did not affect their decision to immunize their children. Only $2.0 \%$ of them said that their religion did not allow them to take immunization. All the $100 \%$ of the respondents were conscious of where to get immunization. Lastly only $96.1 \%$ claimed that vaccines were available but some $3.9 \%$ said vaccines were not available.

TABLE 3: Factors Influencing Mother's Compliance with Immunization

\begin{tabular}{|c|c|c|c|c|c|c|c|c|}
\hline Regimen & $\mathbf{S A}$ & $\mathbf{A}$ & $\mathbf{U}$ & D & SD & $\mathbf{S A}+\mathbf{A}$ & D+SD & $\mathbf{U}$ \\
\hline Health workers' behaviour discourage mothers & 60 & 33 & 6 & 27 & 27 & $\begin{array}{l}93 \\
(60.8)\end{array}$ & $\begin{array}{l}54 \\
(35.3)\end{array}$ & $\begin{array}{l}6 \\
(3.9) \\
\end{array}$ \\
\hline Cost of immunization scary & 21 & 12 & 3 & 6 & 78 & $\begin{array}{l}33 \\
(22.0)\end{array}$ & $\begin{array}{l}84 \\
(54.9)\end{array}$ & $\begin{array}{l}6 \\
(3.9)\end{array}$ \\
\hline Immunization highly effective & 98 & 30 & 9 & 12 & 9 & $\begin{array}{l}128 \\
(83.7)\end{array}$ & $\begin{array}{l}21 \\
(13.7)\end{array}$ & $\begin{array}{l}9 \\
(5.9)\end{array}$ \\
\hline Mothers' work prevent participation & 24 & 18 & 12 & 48 & 63 & $\begin{array}{l}30 \\
(19.6)\end{array}$ & $\begin{array}{l}111 \\
(72.6)\end{array}$ & $\begin{array}{l}12 \\
(7.8)\end{array}$ \\
\hline Vaccination centres are far from abode. & 63 & 24 & 12 & 9 & 12 & $\begin{array}{l}87 \\
(56.9)\end{array}$ & $\begin{array}{l}21 \\
(13.7)\end{array}$ & $\begin{array}{l}12 \\
(7.8)\end{array}$ \\
\hline Time spent too long. & 54 & 30 & 6 & 27 & 36 & $\begin{array}{c}84 \\
(55)\end{array}$ & $\begin{array}{l}63 \\
(41.1)\end{array}$ & $\begin{array}{l}6 \\
(3.9)\end{array}$ \\
\hline Payment of some items discourage participation. & 30 & 4 & 4 & 35 & 80 & $\begin{array}{l}34 \\
(22.2)\end{array}$ & $\begin{array}{l}115 \\
(75.2)\end{array}$ & $\begin{array}{l}4 \\
(2.6)\end{array}$ \\
\hline $\begin{array}{l}\text { Lengthy Contact period. } \\
\text { (Number of visits) }\end{array}$ & 105 & 5 & 9 & 7 & 27 & $\begin{array}{l}110 \\
(71.9)\end{array}$ & $\begin{array}{l}34 \\
(22.2)\end{array}$ & $\begin{array}{r}9 \\
(5.9)\end{array}$ \\
\hline Child been ill. & 70 & 30 & 3 & 23 & 27 & $\begin{array}{l}100 \\
(65.4)\end{array}$ & $\begin{array}{l}50 \\
(32.7)\end{array}$ & $\begin{array}{l}3 \\
(1.9) \\
\end{array}$ \\
\hline
\end{tabular}

Figures in parentheses are percentages.

Table 3 show ten factors that are explored as influencing mothers' compliance with immunization regimen. Majority of $60.8 \%$ agreed with the factor that health workers' behaviour discouraged compliance. About $22 \%$ of the respondents cited the cost of obtaining immunization as barrier to compliance. Some $83.7 \%$ of the mothers agreed that immunization is highly effective for the diseases and this encourages them to comply. $72.6 \%$ of the respondents disagreed with the notion that mothers' occupations constituted obstacle to their participation and compliance. $55 \%$ of them agreed that time spent for immunization was too long. While $65.4 \%$ of .respondents cited child illness as a factor discouraging compliance with vaccines. About $71.9 \%$ of them agreed with contact period as a factor discouraging compliance.

\section{Hypotheses Testing}

\section{Hypothesis 1}

Null Hypothesis: There is no significant relationship between age of respondents and compliance with immunization regimen.

Alternative Hypothesis: There is significant relationship between age of respondents and compliance with immunization regimen.

TABLE 4: The relationship between the Age of the Respondents and compliance with Immunization Regimen

\begin{tabular}{|l|l|l|l|l|l|l|l|}
\hline & \multicolumn{9}{|l|}{ Compliance } & \multicolumn{1}{l|}{} \\
\hline & YES & NO & $\mathrm{X}^{2}$ cal & $\mathrm{X}^{2}$ tab & DF & p-value & Remark \\
\hline Age (Years) & & & ${ }^{\prime} 64.36$ & 5.991 & .2 & $\mathbf{0 . 0 5}$ & Significant \\
$15-25$ & 51 & 18 & & & & & \\
$26-35$ & 66 & 12 & & & & & \\
$36-45$ & 6 & 0 & & & & & \\
\hline- & 123 & 30 & & \multicolumn{6}{|l|}{} \\
\hline
\end{tabular}

\section{$\mathrm{X}^{2}$ cal $=64.36 \quad \mathrm{X}^{2}$ tab, $0.05,2=5.991$.}

The Decision Rule states that If $\mathrm{X}^{2} \mathrm{cal}>\mathrm{X}^{2}$ tab, then reject Ho and accept Hi. Based on the results in Table 3, the alternative hypothesis was accepted. This implies that there is a significant relationship between age of the respondents and compliance with immunization regimen. This means that compliance is dependent on age of the respondents.

\section{Hypothesis 2}

Null Hypothesis: There is no significant relationship between respondent occupation and compliance Alternative Hypothesis: There is significant relationship between respondent occupation and compliance 
TABLE 5: The relationship between respondents`occupation and compliance with immunization regimen.

\begin{tabular}{|c|c|c|c|c|c|c|c|}
\hline & \multicolumn{7}{|c|}{ Compliance } \\
\hline & YES & NO & $\mathrm{X}^{2} \mathrm{cal}$ & $\mathrm{X}^{2} \mathrm{tab}$ & DF & p-value & Remark \\
\hline $\begin{array}{l}\text { Occupation } \\
\text { Farming } \\
\text { House wife } \\
\text { Civil servant } \\
\text { Trading } \\
\text { Students } \\
\text { Combined }\end{array}$ & $\begin{array}{l}3 \\
30 \\
12 \\
59 \\
3 \\
16\end{array}$ & $\begin{array}{l}0 \\
0 \\
3 \\
18 \\
0 \\
9\end{array}$ & 163.8975 & 11.070 . & 5 & 0.05 & Significant \\
\hline Total & 123 & 30 & & & & & \\
\hline
\end{tabular}

$\mathrm{X}^{2}$ cal $=163.8975 \quad \mathrm{X}^{2} \mathrm{tab}, 0.05,5=11.070$.

The alternative hypothesis was accepted on the basis of the results in Table 4. This indicated that there is a significant relationship between the respondents`occupation and compliance with immunization regimen. This indicated that compliance is dependent on respondents' occupation. Compliance depends on the occupations of the respondents.

Hypothesis 3

Null Hypothesis: There is no significant relationship between educational background and compliance.

III. Alternative Hypothesis: There is significant relationship between educational background and compliance.

Table 6: The relationship between education of respondents and compliance with immunization regimen

\begin{tabular}{|l|l|l|l|l|l|l|l|}
\hline & Compliance & \multicolumn{2}{l|}{} \\
\hline & YES & NO & DF & $\mathrm{X}^{2}$ cal & $\mathrm{X}^{2}$ tab & p-value & Remark \\
\hline Educational level & & & 3 & 109.361 & 7.815 & 0.05 & Significant \\
Primary & 33 & 3 & & & & & \\
Secondary & 69 & 21 & & & & & \\
Polytechnic & 12 & 6 & & & & & \\
University & 9 & 0 & & & & & \\
\hline Total & 123 & 30 & & & & & \\
$X^{2}$ cal = 109.361 & $\mathrm{X}^{2}$ tab $0.05,3=7.815$ &
\end{tabular}

The alternative hypothesis was not rejected based on the results in Table 5. There is thus a significant relationship between education of respondents and compliance with immunization regimen. This implies that compliance is dependent on educational backgrounds of the respondents

\section{Discussion}

The study was carried out to examine factors influencing compliance with immunization regimen among nursing mothers in Moniya Community, Ibadan, Nigeria. The majority, $80.4 \%$ of respondents affirmed that they have taken at least one vaccine while $19.6 \%$ claimed they have not taken any vaccine for their children. More so, $62.8 \%$ have fully immunized their last child while the remaining $37.2 \%$ of the respondents did not immunize their children fully. This is consistent with study by ${ }^{4}$ that compared the immunization cards of all the children aged five years and below admitted into the peadiatric wards of the University of Calabar Teaching Hospital, Calabar, Nigeria with the mothers which reported that only 560(60.9\%) were fully immunized for age. 244(26.6\%) partially immunized and $115(12.5 \%)$ had no form of immunization. The prevalence rate of missed opportunity was $39.1 \%$. Most of these patients were in the in the low lower socioeconomic groups.

This study has revealed that the commonest reason for missing immunization was illness of the child at the time of immunization as stated by $65.4 \%$ of the respondents. This was similar to the findings by Goodman, Wu, and Frerich, (2000) conducted a study on compliance rates in Kern County, California and found that parents sited non-compliance as being due mainly to child's illness, procrastination and lack of knowledge about immunization and where to obtain services. Also Babalola (2011) supported this finding.

Other reason include worry about the side effects of immunization $(98.0 \%)$ Their work, religious belief and cost did not really affect their compliance negatively. Furthermore, $98.0 \%$ claimed that their occupations allow them to take their children for immunization. Some $60.8 \%$ agreed with the statement that health workers behaviour discouraged compliance. This is in line with findings by Babalola and Adewuyi (2005) who cited Provider's attitudes and long waiting period as few reasons by mothers for not taking additional immunization for their children. Indeed a few women were frustrated because they had visited the facility more than one time with no vaccines on ground, absence of service providers or disrespectful providers. 
About $22 \%$ of the respondents cited the cost of obtaining immunization as barrier to compliance. Some $83.7 \%$ of the mothers agreed that immunization is highly effective for the diseases and this encourages them to comply. Also $52.9 \%$ of them stated that time spent for immunization was too long. This study is in support of findings of Ekumwe (2004) who hypothesized that shortening the waiting time for patients to be immunized increased the compliance rate. About $71.9 \%$ of them agreed with the contact period as a factor discouraging compliance. This is relevant to the study by Babalola and Adewuyi (2005) which stated that one of the barriers to immunization in Nigeria is the frequent undersupply of vaccines and the need for repeated visits often led to incomplete immunization of children in those that have no easy access to a Primary Health Care services. Only $96.1 \%$ claimed that the necessary vaccines were available.

The hypotheses were tested showed some associations between various variables. The relationship between age of the respondents and compliance with immunization regimen significant. This showed that poor compliance was higher in the younger age groups. The results also showed that there is a significant relationship between the respondents' occupation and compliance with immunization regimen. This indicated that compliance is dependent on respondents' occupation. Compliance depends on the occupations of the respondents. The analysis showed that there is a significant relationship between education of respondents and compliance with immunization regimen. This implies that compliance is dependent on the educational backgrounds of the respondents. The result of the chi square analysis also confirmed a significant relationship between time spent at the immunization centers by the respondents and compliance with immunization regimen. This implies that compliance is dependent on time spent at immunization centers.

\section{Conclusion}

This study attempted to identify factors influencing compliance with immunization regimen among nursing mothers in Moniya Community. The study revealed that, majority of respondents took at least one vaccine, have worry over a side effect of vaccines. Occupations and religions did not constitute barriers to their participation in the scheme. Health workers behavior discourage compliance .Cost of immunization was found to be a barrier to compliance. The respondents claimed that the time spent for immunization was too long .Age, occupation, education. religion and time spent at the centers were found to have significant relationship with compliance with immunization regimen. Compliance therefore depends on these socio-demographic factors. These thus constitute the major factors influencing compliance with immunization regimen in the area of study.

\section{Recommendations}

There is the need to encourage nursing mothers to comply fully with the scheme through rigorous immunization awareness/campaigns workshops and seminars on benefits of immunization

Health workers should be tutored on sound work ethics and behaviour to their client. They should be clientfriendly as this variable indicated positive contribution to compliance by the respondents. There is the policy need to find a way of reducing the cost of immunization. The clients claimed the high cost constitute a barrier to their compliance with the immunization regimen . The cost of immunization should be reduced so as to allow many more clients into the scheme

Respondents claimed that the time spent at the centers was too long a reduction in the time is expected to further encourage not only participation but also compliance with the regimen.

\section{References}

[1]. Federal Government of Nigeria, Federal Ministry of Health and National Programme on Immunization (2004). 5 years National Strategic Plan. 2004-2008 Abuja FGN.

[2]. Babalola S 2011. Maternal reasons for non-immunization and partial immunization in northern Nigeria. Journal of Pediatric and Child Health. 47(5):276-81

[3]. United Nation's Development Programme (UNDP) (2004). Human Development Report. New York.

[4]. World Health Organization (2005). An Evaluation of Infant Immunization in Africa a Transformation in Progress 6. Vol. (85) 42 1500. Geneva.

[5]. World Health Organization (2010). Bulletin of the World Health Organization. Vol. (5). 210-350 Geneva

[6]. United Nation's Children's Fund (UNICEF) (2002). Evaluation Report NGR 2002/2004 National Review of the National Programme on Immunization in Nigeria.

[7]. Smith and Marrow, (2003). Risk Factors for Delay in Age-appropriate Vaccination. U.S. Department of Health and Human Services; Public Health Reports, 119, 144-155. http://web.lexis-nexis.com.

[8]. Akinsola H.A. (2006) A-Z of Community Health in Medical, Nursing and Health Education Practices ( $2^{\text {nd }}$ ed)( College Press and Publisher Limited. Mosaderin Road, Jericho GRA, Ibadan. Oyo State.)

[9]. National Population Commission (NPC) Nigeria and ICF Macro 2009. Nigeria Demographic and Health Survey 2008.Abuja : National Population Commission and ICF Macro

[10]. Owolabi, B. (2010). Review of Immunization Schedule in Oyo State of Nigeria by Oyo State Ministry of Health, Health System Information Unit.

[11]. Adeolu, K.G. (2001). Self Concept and Health Beliefs in Compliant and Non-Compliant Hypertensive Patients Nursing Research, vol. $30323-328$

[12]. Ajayi, F.T. (2004). A Guide to Primary Health Care Practice in Developing Countries: $4^{\text {th }}$ edition. (Felicity Print Limited Akure.) 
[13]. Babalola, S. and Adewuyi, A. (2005). Factors Influencing Immunization Uptake in Nigeria. A Theory-based Research in Six States. Abuja PATHS.

[14]. Anah, M. U., Etuk, I. S., Udo, J. J. (2006). Opportunistic immunization with in-patient programme: eliminating a missed opportunity in Calabar, Nigeria. Annals of African Medicine, 5(4):188-191

[15]. Sadoh, A. E.; Eregie, C. O. Timeliness and Completion Rate of Immunization Among Nigerian Children Attending a Clinic-Based Immunization Service. J Health Popul Nutr; 27 (3): 391-395; June, 2009.

[16]. Goodman, K. Wui J, and Frerichs R. (2000). Compliance with Childhood Immunisations in Kern County, California. Journal of Immigrant Health (4) 213-322.

[17]. Bundt, T. S.; Hu, H. M. National Examination of Compliance Predictors and the Immunization Status of Children: Precursor to a Developmental Model for Health Systems. Mil Med. 169 (10): 795-803; October, 2004.

[18]. Parve, J. (2004). Remove Vaccination Barriers for Children 12-24 months. The Nurse Practitioner 29. vol. 4. $35-38$.

[19]. Becker M.H. (1979). The Health Belief Model and Personal Health Behaviour. New York Thorofare.

[20]. Goyea, K. and Lantz, P. (2007). Risk Factors for Delay in Age - Appropriate Vaccination. Department of Health and Human Services. Public Health Reports 119, 144-155.

[21]. National Population Commission (NPC) Nigeria and ICF Macro 2009. Nigeria Demographic and Health Survey 2008.Abuja : National Population Commission and ICF Macro

[22]. Parve, J. (2004). Remove Vaccination Barriers for Children 12-24 months. The Nurse Practitioner 29. vol. 4. 35 -38. 